\title{
儒家和同性婚姻
}

\section{Confucianism and Same-Sex}

\section{Marriage}

李勇

Li Yong

\section{Abstract}

Fang Xudong argues that there are no successful arguments against same-sex marriage but that Confucianism does not prefer same-sex marriage. In particular, Fang objects to the slippery-slope argument against same-sex marriage, arguing that it is not successful. This commentary contends that the slippery-slope argument cannot be defeated based on the idea of equal marriage rights. I argue that Fang's reasoning for the Confucian preference to avoid same-sex marriage, based on the importance of natural conception and natural birth, is not valid. Furthermore, I argue that the idea of heterosexual union might not be essential for Confucian key doctrines.

方旭東教授在《權利與善——論同性婚姻》一文中論述了兩 個觀點：第一、他不反對同性婚姻合法化; 第二、儒家推崇異性 婚姻。方教授對於這兩個觀點都給出了論證。本文主要是指出其 論證中值得商榷的地方。

李 勇, 武漢大學哲學學院副教授, 中國武漢, 郵編 : 430072。

Li Yong, Associate Professor, School of Philosophy, Wuhan University, Wuhan, China, 430072 .

《中外醫學哲學》XVI:2 (2018 年) : 頁 131-135。

International Journal of Chinese \& Comparative Philosophy of Medicine XVI:2 (2018), pp. 131-135.

C Copyright 2018 by Global Scholarly Publications. 
關於第一個論點，方教授不反對同性婚姻合法化。這個論點 有兩種解讀。強的解讀：方教授支持同性婚姻合法化; 弱的解讀 : 方教授不反對，但也不支持同性婚姻合法化。方教授在文章中指 出, “筆者推崇異性婚姻, 但筆者也僅僅是陳述異性婚姻優越的 道理，並不謀求政府通過立法或制定相關政策禁止同性婚姻”。 所以, 方教授不接受強的解讀, 方教授不反對同性婚姻合法化, 但他也不支持同性婚姻合法化。

方教授不反對同性婚姻合法化, 主要是因為“反對同性婚姻 合法化” 的論證都有各種問題。方教授列舉了自然論證、起源論 證、歸謬論證、危害傳統婚姻論證、具體人權論證。我這裡想指 出, 他對於歸謬論證的回應不夠充分。他對於歸謬論證理解如下:

(1) 如果同性婚姻合法, 那麼任何建立在當事人自願基礎上的 婚姻都是合法的, 比如亂倫婚姻、一夫多妻或者一妻多夫、人獸 之間等等。

(2) 亂倫婚姻、一夫多妻或者一妻多夫、人獸之間的婚姻不是 合法的。

因此，

(3) 同性婚姻不合法。

方教授對以上的論證的主要回應是：首先, “自願原則不是 支持同性婚姻的主要理由, 更不是唯一理由”。在他看來, 同性 婚姻合法性更多來自於憲法中的“保障人民婚姻自由” 條款。其 次, 他認為討論諸如亂倫等婚姻形式是否合法, 和討論同性婚姻 是否合法是不同的法律討論, 需要一事一議。同時, 法律和道德 有嚴格區分, 即使諸如亂倫等婚姻違背道德, 並不能推出其不合 法。

以上對於同性婚姻的歸謬論證, 也被很多學者稱之為滑坡論 證。滑坡論證的基本結構是，如果基於原則 $\mathrm{X}$ 基礎上的 $\mathrm{A}$ 成立, 那麼基於同樣原則基礎上的 $\mathrm{B}$ 也成立; 但是, $\mathrm{B}$ 不成立。因此 $\mathrm{A}$ 也不成立。如果按照方教授的理解, 同性婚姻合法性更多來自於 
憲法中“保障人民婚姻自由”，實際上仍然逃脱不了滑坡論證。 以亂倫婚姻為例。如果母子二人都是成年人, 都有自主能力表達 認同（consent），憲法是否也要保障他們二人的婚姻自由? 方教 授以上的三點回應可能面臨如下幾個問題。首先, 保障婚姻自由 的法律條款, 更多的可能是來自對公民權利的保障, 比如在婚姻 選擇上的自由權。而這種自由權是對公民的自主性和尊嚴的認同 和保護。但是, 這種自由權的保障, 不可避免會出現公民會根據 自己的取向和意願, 進行多種選擇。如果堅持權利論證的話, 在 原則上講, 如果不涉及到 “對他人的傷害” 或者 “對他人尊嚴或 者權利的冒犯” 的話, 兩個自主性個體是可以擁有婚姻或者其他 很多選擇的自由。換句話説, 基於權利的原則, 同性婚姻和亂倫 婚姻應該都得到允許。其次, 關於法律的基礎, 雖然存在實證主 義、功利主義、非功利主義等的爭論, 具體的法律條文不一定直 接建立在特定的道德原則基礎之上, 但是如果一個法律規定背後 的原則, 確實和大多數人接受的道德原則相衝突, 很難想像這個 法律規定的合法性來自何處。換句話説, 如果同性婚姻真的在道 德上和亂倫婚姻一樣聲名狼藉, 很難想像其在法律上能夠得到保 護。

歸謬論證背後隱藏了對同性婚姻的一個更基礎性的挑戰：建 立在婚姻平等權或者權利基礎上的同性婚姻合法化論證根本無法 成功。我的觀點是, 如果要支援同性婚姻的話, 需要尋求後果論 證, 而不是權利論證：同性婚姻對於同性伴侣, 對於整個社會都 是有益的; 一個允許同性結婚的社會比一個不允許同性結婚的社 會更好。

關於方教授的第二個觀點, 儒家推崇異性婚姻, 方教授給出 了兩個理由: 首先, 在傳統儒家來看, 婚姻最重要的功能是繁衍 後代, 同性婚姻在這方面有天然的缺陷。其次, 儒家強調夫婦作 為五倫之一, 對於個人倫理關係的重要性, 同性婚姻不具有這種 夫婦關係的倫理完整性。 
關於第一個理由，方教授也承認，同性伴侶可以通過收養、 代孕等方式解決子嗣問題。但是他指出, “我們要的是父母親生 的孩子, 而不是收養來的; 就某對夫婦而言, 沒有經歷過結合、 懷孕、生產的過程, 他們作為結合體的那種體驗會有很大損失”。 而且“通過收養方式撫養孩子的同性婚姻、家庭將原本自然的一 個過程割裂開來, 它在個體心理與社會層面都會造成巨大的影 響” 。方教授這裡認為肯定是負面的影響, 諸如離婚對孩子的影 響一樣。

我認為, 自然受孕和分娩的那種體驗確實很獨特, 但是給予 這種獨特的體驗以道德價值, 認為有這種獨特體驗的婚姻方式比 沒有這種獨特體驗的婚姻方式在道德層次上更高的觀點, 面臨很 多挑戰。如果繁衍後代確實是婚姻的最重要的功能, 那麼不管一 對伴侶通過何種方式繁衍後代, 都是可以的。當然, 如果方教授 認為, 婚姻的最重要的功能不僅僅是繁衍後代, 還涉及到和自然 受孕和分婏相關的獨特的體驗, 那麼, 確實, 缺少這種體驗的繁 衍後代的方式, 與有這種體驗的繁衍方式相比, 確實是一種損失。 但是，很少有儒家學者去強調這種自然受孕和分娩的 “體驗” 的 重要性。換句話説, 他們似乎並不認為, 自然受孕和分娩的 “體 驗” 對於繁衍後代是至關重要的。儒家所強調的陰陽等形而上的 層面, 和這裡的 “體驗” 並不是一回事。換句話説, 一對伴侶, 通過人工代孕的方式, 繁衍了後代, 似乎滿足了儒家對於婚姻的 要求。

關於第二個理由, 毫無疑問, 在儒家傳統中, 異性構成的夫 婦, 而不是同性構成的夫婦是五倫之一。就像在基督教傳統裡, 聖經中討論的夫婦, 肯定是異性構成的。儒家、基督教和任何的 宗教和文化傳統都面臨類似的問題：自己經典中對婚姻等習俗的 觀點, 是否是這個傳統的內核。如果是內核的話, 放棄了這個內 核, 就意味著改變或者放棄了這個傳統。這裡涉及到兩個問題 : 首先, 異性構成的夫婦是否是儒家傳統的內核? 其次, 如果是儒 
家傳統的內核（之一）, 對這個內核的改變或者放棄, 意味著什 麼?

關於這兩個問題, 方教授肯定是認為: 異性構成的夫婦是儒 家傳統的內核; 對這個內核的改變或者放棄, 儒家就不是儒家了。 基於概念維度, 以上結論可以討論。如果是基於歷史的維度來看, 夫婦制度肯定是在儒家出現之前就存在。異性婚姻制度的產生、 發展、變遷, 在世界範圍內, 肯定是不以某種哲學觀點為基礎的。

\section{參考文獻 References}

方旭東：〈權利與善：論同性婚姻〉, 《中外醫學哲學》, 2018 年, 第 XVI 卷, 第 2 期, 頁 99-114。FANG Xudong. "Rights and Goods: On Same-sex Marriage,” International Journal of Chinese \& Comparative Philosophy of Medicine XVI:2 (2018), pp.99-114. 